\title{
Correction to: Reconceptualizing Quality in Early Childhood Education, Care and Development
}

\author{
Zoyah Kinkead-Clark and Kerry-Ann Escayg
}

\section{Correction to:}

Z. Kinkead-Clark, K.-A. Escayg (eds), Reconceptualizing Quality in Early Childhood Education, Care and Development, https://doi.org/10.1007/978-3-030-69013-7

The first paragraph of the chapter 1 has been deleted and added to the abstract in the online version of this chapter.

In addition to this, the order of author names in Chapter 2 has been updated from John P. Portelli and Darya (Dash)Shalimo to Darya (Dasha) Shalimo and John P. Portelli.

The updated version of these chapters can be found at https://doi.org/10.1007/978-3-030-69013-7_1

https://doi.org/10.1007/978-3-030-69013-7_2 